\title{
USOS DA ARQUEOLOGIA NA SALA DE AULA
}

\section{T. O. Miller ${ }^{1}$}

\section{RESUMO:}

O autor, arqueólogo antropológico e sistêmico, começa por definir os campos de atuação da Arqueologia, com as suas possibilidades e limitações e com a sua importância em relação à nossa memória social futura, pois as soluções para o futuro têm que levar em conta a experiência do passado. Isto é relevante porque o Homem não tem se modificado, geneticamente, de nenhuma maneira substancial durante os últimos 50.000 anos. Discute a natureza social do Homem e os seus métodos de adaptação e co-participação em relação ao ambiente, a luz de conhecimentos arqueológicos, etnográficos e históricos. Compara a nossa atuação em relação aos mesmos ambientes com a de outros povos do passado e do presente. Examina comparativamente, também, os trajetos de diversos povos, bem ou mal sucedidos, em relação a problemas que nos enfrentam hoje, abrindo novas perspectivas sobre o presente e o futuro. Mostra também onde a Arqueologia pode oferecer certa profundidade temporal em relação aos contextos vistos no "presente etnográfico", inclusive as limitações de certas conclusões tiradas dos dados etnográficos no passado, os quais passaram ao conhecimento geral sem serem contestados. Depois considera casos no passado onde os povos enfrentaram e se sucumbiram a problemas, semelhante aos que hoje enfrentamos, sem os nossos detentores do poder decisório saberem que as nossas idéias são semelhantes às deles e, sem saber desses acontecimentos do passado. Em seguida, o autor examina diversas situações de sala de aula onde as lições da Arqueologia servem no ensino não só da História, mas, também, de situações práticas de metodologia científica. Finalmente, usa dados fornecidos conjuntamente pela Arqueologia e outras ciências, numa abordagem transdisciplinar, para situar questões "quentes" dos nossos tempos, tais como os conceitos de Tempo, de Sobrevivência e Maximização e, ainda, de Progresso, tudo a luz de outros pontos de vista derivados da experiência de outros povos.

Palavras-chave: Arqueologia; conhecimentos arqueológicos; História; memória social

\section{SOME USES OF ARCHAEOLOGY IN THE CLASSROOM}

\begin{abstract}
:
The author defines the areas of archaeological activity, with its limitations and possibilities and with its importance in terms of our future social memory. He discusses the social nature of Man and his methods of adaptation and co-participation with the environment in the light of archaeological, ethnographic and historical knowledge. He compares our situation with regards to the same habitats with that of other peoples of the past and present which confronted or succumbed these problems. Next the author examines various classroom situations where the lessons of archaeology serve not just history but also practical situations of scientific method. Finally, he uses information furnished by archaeology in combination with other sciences in a trans-disciplinary approach, in order to focus on "hot" issues of our times - such as the concepts of Time, of Survival our Maximizing and Progress, all in the light of other viewpoints derived from the experience of other peoples.
\end{abstract}

Key Words: Anthropology, Teaching of Anthropology, Contemporary problems. 
Desde o início da sua existência o homem ocupa o seu espaço na superfície do Planeta, fazendo sempre as suas modificações de acordo com as suas necessidades e com a tecnologia da época. As atividades humanas do passado, inclusive, passam a integrar permanentemente a paisagem, onde modificações feitas por grupos posteriores vêm-se sobrepor às de grupos anteriores, configurando, desse modo, um processo contínuo.

$\mathrm{Na}$ quase totalidade desses casos, por não existir registro escrito de tais atividades, somente o especialista pode recuperar a "memória" dos eventos envolvendo os nossos antepassados. Convém ressaltar, contudo, que qualquer modificação atual da paisagem estradas, barragens, cultivo, construção, desmatamento, etc. - destrói irremediavelmente uma parte da nossa memória coletiva. A ciência que trata dessa parte da nossa memória patrimonial chama-se Arqueologia.

Em geral, pensa-se a Arqueologia como a ciência que fornece dados de suporte para as descrições históricas, ou ainda para descobrir e registrar a história onde ela não foi registrada pelos contemporâneos dos eventos. Todavia, a Arqueologia não se resume a tal, pois tem outras contribuições a apresentar.

Estamos nos pronunciando, enquanto autor, como arqueólogo antropológico e sistêmico, pois é essa a nossa área de atuação. Nesse âmbito, o trabalho de campo e de laboratório tem o seu próprio conjunto de métodos e técnicas, embora quando se chegue à interpretação, o que se tem mesmo é antropologia - seja do passado ou do presente.

\section{A - O que faz a Arqueologia?}

A Arqueologia analisa, identifica e estuda os vestígios materiais dos povos desaparecidos, com o objetivo de conhecer melhor a vida dos nossos antepassados e os problemas enfrentados e solucionados (ou não) no passado.

Protegendo hoje esses objetos e vestígios do passado, estaremos salvaguardando e garantindo a compreensão e perpetuação da nossa memória social futura. Além disso, nenhum povo pode prosperar sem a memória do seu passado, pois as soluções para o futuro têm que levar em conta a experiência vivida.

Tradicionalmente, entendia-se a Arqueologia como o estudo de povos préhistóricos ou pré-letrados. Estes não deixaram textos escritos pra que pudéssemos ler a sua história. Uma vez que a Arqueologia só pode lidar com objetos materiais que sobreviveram à ação corrosiva do tempo e ao contexto dentro do qual se inseriam, paulatinamente essa disceplina passou também a ser o estudo do desenvolvimento da tecnologia, sendo esta entendida como o instrumental (material) que serve de mediador entre homem-homem e entre homem-ambiente, bem como o conhecimento (informação) necessário para sua fabricação e uso.

O Homem do passado vivia em grupos em ambientes diferentes, com a tecnologia necessária para a sua sobrevivência. A sua herança de informação genética praticamente não passou por qualquer mudança significativa nos últimos 50.000 anos. A única diferença entre esse Homem e o de hoje é a sua tecnologia acumulada - o aumento da informação sendo uma das concomitantes da evolução, seja esta genética ou cultural.

Disto podemos inferir que a informação que ganhamos sobre como o Homem do passado se relacionava com o seu ambiente físico e social é relevante para melhor entender a nossa situação atual.

Uma constatação dos antropólogos e arqueólogos é que os seres humanos vivem em grupos organizados em territórios próprios. Precisam se abastecer de energias e matérias 
primas para a sua sobrevivência, sendo a fonte dessas energias e matérias o seu ambiente físico-geográfico.

A maneira de os seres humanos lidarem com o seu ambiente para sele extraírem o necessário para a sua sobrevivência envolve, diferentemente dos casos de todas as outras espécies vivas, uma variedade extraordinária de instrumentos e facilidades manufaturados para essa finalidade, - o "instrumental" (nos termos de MALINOWSKI, 1970) usado pelo "pessoal" organizado em "instituições".

O arqueólogo Lewis BINFORD $(1962,1964)$ considera que o enfoque de pesquisa deve ser o "palco" onde um grupo de "atores" (o "pessoal" de Malinowski) desempenhou atividades organizadas de "extração" (de energias e matérias) do ambiente, ou que "transformou" (processou) tais matérias para produzir instrumentos ou energias utilizáveis (p. ex., alimentos). Sendo a atividade organizada, essa deixaria também o seu reflexo na organização dos instrumentos e das modificações do palco que os atores abandonaram após terminarem a sua atividade.

\section{B - Ambientes e Opções}

A Arqueologia Antropológica pode nos ensinar muita coisa sobre o passado, possibilitando, assim, uma nova perspectiva sobre o presente e o futuro. Como frisamos, o Homem se insere num ambiente e o ambiente lhe fornece oportunidades e limitações sobre as suas opções. Ele pode aproveitar-se daquelas e superar, ou não, estas de acordo com os rumos imprimidos na sua programação biológica e cultural.

Ressaltamos que tanto existem diferenças entre ambientes quanto entre os programas biológicos e culturais. Acrescentando-se a essas diferenças o fator da Historicidade $^{2}$ (ver as Notas no fim), teremos todos os ingredientes para uma infinidade de possibilidades. E, tem mais: há fatores que limitam ou inibem o número de escolhas dentre as opções, os quais podem afunilá-las para uma gama menor de resultados possíveis.

Como estamos, ainda, tentando entender as interações causais entre esses fatores, vamos começar com o ambiente.

\section{(1) Adaptação e Co-participação}

Quando um homem do povo Hopi Pueblo do Arizona, na América do Norte, sai à procura da planta medicinal adequada para um determinado fim, ele não colhe o primeiro exemplar que encontra: ao contrário, deixa um palito-de-rezar - um pauzinho decorado com símbolos sagrados - ao lado da planta como sinal de respeito, e vai procurar outra. $\mathrm{O}$ leitor vai pensar logo nisso como um exemplo da superstição de um primitivo.

Entretanto, tal ato garante a sobrevivência da espécie em questão num ambiente árido, fazendo parte da visão do mundo do hopi de que o homem, longe de estar aqui para dominar e explorar o Universo, é um co-participante na comunidade maior da Natureza, a nossa biosfera. Para o hopi os seres humanos, especificamente, são membros dessa comunhão e têm a responsabilidade de se esforçar para garantir a ordem e a harmonia no Universo, senão, o caos tomaria conta deste. Embora este esteja-nos custando aprender esta idéia, a nossa sobrevivência depende dela.

Tal visão hopi do Universo, como um total harmoniosamente integrado de partes diferentes ou desiguais, reflete-se até na sua arte, onde vemos um equilíbrio assimétrico entre unidades de formas e tamanhos diferentes - uma arte mais sinfônica de que decorativa. 
Também vale a pena falar da distinção que fazemos entre a função de uma determinada prática ${ }^{3}$ e o significado desta. A função da prática hopi de deixar a primeira planta viver tem a função de parcialmente garantir um suprimento futuro de tal planta.

O significado, por outro lado, diz respeito à razão pela qual o povo é motivado a fazer uma determinada coisa e não outra: no caso, uma expressão de "respeito" aos poderes e posição (sobrenatural) da planta na comunidade dos vivos. Isto não qualquer relação com a função, a não ser garantir que o povo pratica atos que têm o resultado sistêmico desejado, mesmo que pelas razões erradas - bastando que haja resultados positivos.

Deste modo, como notamos, a ação na base do significado pode até conduzir a um resultado positivo que nada tem a ver com o significado em si: os índios kaiapós não matam os animais mais gordos ("bonitos") que encontram perto das suas comunidades porque, no seu entender, eles (os animais) têm espíritos mais fortes e, mortos, podem causar danos às pessoas da comunidade. Isto tem como conseqüência que tais animais poupados, com as suas características de maior produção de quilos de carne por indivíduo, vivem mais tempo para propagar as suas tendências genéticas para mais prole (seleção), melhorando, assim, o estoque genético para a produção de carne na região (função). Os kaiapós, contudo, não sabem disso. Apenas eles têm medo dos espíritos fortes. Entretanto, isto bastava para garantir a carne boa no seu cardápio.

Os seres humanos não agem de acordo com o Universo objetivamente real, mas, antes, de acordo com o seu modelo mental do Universo, o que não é a mesma coisa. É por isso que o povo de um sistema sociocultural não precisa saber a função de uma determinada prática, desde que esta lhes traga os resultados de que o sistema necessita. Todavia, tal povo precisa de uma motivação, e é por isso que temos o significado.

\section{(2) Inserção num Ambiente Físico - Possibilidades e Limitações}

Possibilidades do Ambiente: Sempre existiu uma grande quantidade de minério na Serra dos Carajás, mas os índios que nela habitavam não aproveitaram de tal riqueza, por não terem se dado conta dela, uma vez que esta não fazia parte de sua visão do mundo. Fazia parte, sim, do seu ambiente físico, mas não do seu ambiente efetivo ou cognitivo. É por isso que fazemos esta distinção entre o Ambiente Físico e o Ambiente Efetivo.

Os índios Coeur d'Alêne (Skitsmish), do noroeste da América do Norte viviam num ambiente de densas florestas temperadas cortadas por inúmeros rios e lagos, os quais eram aproveitarados tanto como via para o seu deslocamento quanto como fonte de alimento. Só que, depois da conquista desse território e incorporação pelos Estados Unidos, tais índios foram despojados das suas lindas praias e vias aquáticas e colocados numa reserva de floresta fechada - ambiente que eles mal conheciam e certamente temiam. Um índio desse povo era capaz de viajar 300 quilômetros de canoa para não ter que atravessar vinte quilômetros de floresta a pé.

Ao mesmo tempo, os norte-americanos estabeleceram uma rede de comunicação fluvial com barcos a vapor para transporte de minério, operários, soldados e produtos pela região, precisando, portanto, de lenha para as caldeiras dos barcos. Prontamente, os índios começaram a desmatar a floresta para vender a madeira, em troca de, entre outras coisas, poder andar de barco de graça. Ao desmatarem a região, os índios descobriram que, embaixo da floresta, havia um solo riquíssimo de origem eólica (solo paloose loess), ideal para o cultivo do trigo. Isto levou-os a se tornarem fazendeiros de uma parte das melhores terras para produção de trigo no continente, e os brancos passaram a se morder de raiva 
porque, ao deixarem a floresta (inútil para eles naqueles tempos) para os índios, não sabiam do valor do solo embaixo. Àquelas alturas, porém, o "mal” já estava feito.

Similarmente, os índios do sudeste do mesmo país foram expulsos das suas terras e colocados numa reserva de terras áridas, aparentemente muito pobres, no semi-deserto de Oklahoma. Só depois é que foi descoberto o petróleo na região, deixando os índios ricos e os brancos furiosos, porque, mais uma vez, o "mal" já estava feito. $\mathrm{O}$ ambiente físico não mudara, mas, nos dois casos, a percepção do ambiente (ambiente efetivo) sim.

Limitações do Ambiente: O Ambiente Físico também pode impor limitações que só podem ser superadas por alargamento do Ambiente Efetivo, explorado através de mecanismos tais como o comércio.

Depois dos povos filipinos e dos ilhéus do Pacífico Ocidental terem caído sob a influência dos malaio-indonésios, por sua vez sob influência indiana, eles usaram o conhecimento indiano-indonésio de navegação para colonizar todas as ilhas do Pacífico. Ao fazerem isto, na opinião dos antropólogos do século XIX, tais povos regredirem da Idade do Ferro (barbárie) para a Idade da Pedra (selvageria). Isto porque o que não possuíam mais a metalurgia nem a cerâmica, embora continuassem a praticar a horticultura e a criação de animais de pequeno porte. Por quê?

Os territórios ocupados pelos polinésios e micronésios são ilhotas formadas pelos picos de vulcões que emergiram das águas, ou por recifes de coral formados em volta do pico da cratera de vulcões submersos, mas perto da superfície. O solo vulcânico é rico para a agricultura e o solo formado pelo coral também pode ser cultivado. Esse tipo se solo, todavia, não possui minério de ferro nem argila para a confecção da cerâmica.

Ao contrário dos antropólogos da época, isto não é a involução cultural, é apenas a privação. Esses povos continuavam a ter chefias desenvolvidas, frequentemente à beira da formação do Estado, o que foi alcançado muito facilmente pelos havaianos, samoanos, tonguenses e outros. A sua arte de navegação ainda continuava tão boa quanto a de outros povos, até que os europeus absorveram essa arte dos árabes (que a derivaram, também, dos indianos) e a combinaram com a construção de fortalezas flutuantes.

Combinações e recombinações de fatores: Um caso muito interessante é o dos povos tupi-guarani de América do Sul. Sabemos por evidências históricas e arqueológicas que esses povos se expandiam de um ponto de origem na Amazônia e ocuparam uma grande parte do lado leste do continente. Caso semelhante aconteceu com os povos bantos da África.

Nos dois casos, sabemos que a sua expansão foi possível por uma tecnologia que lhes deu maior eficiência na exploração do seu ambiente, deslocando os povos autóctones para ambientes de menor produtividade. No caso banto, por exemplo, foi a tecnologia do ferro que eles desenvolveram. Tal tecnologia eles desenvolveram, provavelmente, independentemente da produção homóloga da Ásia, porque a tecnologia é distinta.

O caso dos guaranis e tupis, um grupo de povos de língua e cultura muito semelhantes entre si, é mais bem entendido porque eles ainda estavam em processo quando os europeus chegaram para, por sua vez, deslocá-los ou absorvê-los. A tecnologia que dava vantagem a esses povos era a do processamento da mandioca, uma planta tóxica, mas altamente produtiva de carboidratos. Parece também que a tecnologia por eles desenvolvida para a obtenção de proteína de origem aquática também dava maiores resultados do que os modos da procura de proteína de animais terrestres dos seus inimigos.

Sendo assim, pode-se afirmar que foi um chefe tupi pré-histórico que resolveu conquistar o mundo? Não. Os tupis seguiam um mito, o mito da terra sem males, o que fazia com que qualquer grupo de pessoas insatisfeitas com o seu mundo partisse à procura 
desse paraíso perdido. É claro que ao assim fazerem, eles entravam em conflito com os que já habitavam as terras invadidas. No entanto, a tecnologia citada permitia que criassem um contingente de pessoas maior do que o que podia ser sustentado pela horticultura das suas vítimas. Uma vez estabelecido, o grupo logo se tornava tão numeroso que não podia ser derrotado pelo número inferior das suas vítimas, que terminavam por se retirar para terras que não serviam para a produção de mandioca. O arqueólogo José Proenza Brochado mostrou que os tupis e guaranis já tinham ocupado quase todos os territórios cujo clima permitia o cultivo da mandioca, quando os europeus chegaram. Mas, ressaltamos, não conseguiram ocupar outros ambientes, como por exemplo, os planaltos frios de araucária, que ficaram para os kaingángs e xóklengs e, os campos abertos, que ficaram para os otis.

A expansão tupi deu-se na realidade devido a uma combinação de três fatores, sendo um tecnológico (material), outro, referente à ocupação de ambientes permissíveis (percepção do Ambiente Efetivo) e um outro, mítico (idéia).

As sociedades humanas nunca aproveitam de todos os recursos disponíveis no seu Ambiente Físico, pois há uma seleção sistêmica feita pela sociedade através das suas normas ${ }^{4}$. Por exemplo, muitos povos apreciam iguarias como gafanhotos e formigas de mel, enquanto outros os deixam fora do cardápio. Como fontes de proteína, tais alimentos são altamente ricos. Outros povos, por sua vez, sentem o mesmo nojo em relação a ovos ou a leite de vaca ou de cabra.

Assim, quando os primeiros europeus chegaram à Austrália, ficaram com nojo de ver os aborígines comendo lagartos, grilos e formigas de mel. Não sabiam, mas os nativos sentiram o mesmo nojo ao vê-los comendo "aranhas do mar" (caranguejos).

A Relação Recíproca Homem-ambiente: O ambiente, longe de ser estático, modifica-se e é modificado pelas ações humanas, que também se modificam (através do acúmulo de informação) durante o processo (um exemplo de historicidade). Tais relações circulares intercausais múltiplas só se tornaram compreensíveis com o advento da Teoria de Sistemas (ver MILLER, 2009b).

Há tanto tempo que os xavantes e outros povos do Centro-Oeste vêm botando fogo na mata pouco antes da época das chuvas que as plantas - árvores e arbustos - se adaptaram a tal situação criando raízes que alcançam maior profundidade e caules com cascas fortes. No período da seca, os fluidos vitais passam para as raízes. Por quê? Para resistir às queimadas. Essas queimadas, por sua vez, produzem cinzas (das folhas e plantas menores incineradas) que, em combinação com as chuvas, fornecem um ambiente rico para os gramináceos, os quais são as primeiras plantas que nascem depois das chuvas. Isto, por sua vez, produz mais pastagem para criar maior biomassa de animais portadores de carne. Tem sido notado que esse tipo de ambiente, chamado de cerrado, estava em expansão há muito tempo, tendo sido ajudado, portanto, pelo homem.

A própria agricultura envolve grandes modificações ambientais, pelo cultivo - que envolve a substituição da vegetação dominante - e pelo esgotamento mineral e orgânico do solo. A necessidade de cuidar das plantas cultivadas tornou o Homem sedentário, mesmo querendo carne na mesa, à semelhança do que fizera, anteriormente a pesca em áreas ricas em moluscos. O esgotamento do solo, porém, exigiu uma nova adaptação por parte dos lavradores, que tinham que brocar novas roças, abandonando as velhas à ação do mato, contribuindo assim para um processo de regeneração.

\section{(3) As Lições do Passado aplicadas ao Presente - para garantir o Futuro}

Várias civilizações se iniciaram ao desenvolver uma tecnologia para manipular grandes quantidades de água: captação, armazenamento e redistribuição. São as 
"Civilizações de Regadio" ou "Civilizações Hidráulicas", às quais Marx chamou de "Modo Asiático de Produção". Algumas, como na Mesopotâmia e no Vale do Indo, existiram por milhares de anos. A tecnologia dessas civilizações possibilitou a utilização altamente produtiva de terras que, no regime agrícola dependente da chuva, não seriam propícias para o cultivo.

Mas, a maioria dessas são "civilizações perdidas", extintas. Por quê?

A água da chuva não tem nada de sal, embora este seja altamente solúvel. As águas do rio, por sua vez, contêm pequenas quantidades de sal em solução - pequenas, mas presentes. Quando se leva essa água para o solo, ela se evapora - mas a pequeníssima quantidade de sal não. Permanece depositado lá. A quantidade anual é ínfima mas a acumulação através de séculos e milênios não o é. O solo acaba acumulando sal até o ponto de se tornar improdutivo para a agricultura. Com a diminuição do fornecimento de alimento, o povo passa fome e isso acaba por levá-lo a praticar violência - guerras com os vizinhos, banditismo, dissolução social, dentre outros. Suméria e Babilônia são nomes de coleções de museus, e nem sabemos ler o que o povo do Indo escreveu. Tudo perdido.

Nos dias atuais, temos como exemplo ser citado a reunião promovida pela PETROBRÁS, na década de 1990, em Mossoró, sobre o impacto ambiental de projetos nas terras áridas do Rio Grande do Norte. Alguns dos participantes desse evento insistiram que a empresa citada devia liberar os poços abertos na prospecção para petróleo que, posteriormente eram lacrados por só produzirem água salobra. Argumentaram eles que o nível de sal não ia prejudicar a produtividade do solo (em curto prazo). Não estavam pensando no longo prazo, quando o efeito CUMULATIVO iria destruir qualquer possibilidade de cultivo durante milênios. Foi necessário que este arqueólogo chamasse a atenção a estes fatos históricos.

Outro problema que o passado pode elucidar é o do desmatamento. O advento do neolítico significava que as florestas acabaram sendo derrubadas para dar lugar às roças. Nas florestas da Europa e América do Norte isto não trouxe problemas, ao menos inicialmente. Mas, em áreas tropicais, onde o grau de lixiviação do solo é maior, a história era outra. Na região do atual Saara, encontramos sítios arqueológicos com arpões e anzóis, e as pinturas rupestres figuram animais típicos das savanas na atual África do Sul e Oriental. As queimadas das roças acabaram intensificando um processo incipiente de desertificação, ao ponto de torná-la irreversível. Antes, as condições eram semelhantes às da Amazônia e do Centro-Oeste de hoje, em termos de solo e regime pluviométrico. Evidentemente, a história vai se repetir aqui também. O que é necessário é que se procure aproveitar as lições do passado.

A história climática de América do Sul, como revelada pela Geomorfologia, Geologia do Quaternário e pela Arqueologia, mostra ciclos de calor e aridificação, com enxurradas sazonais, com ciclos de suavização climática, seguidos de crescimento das matas. Estamos entrando numa nova época de aumento de calor ambiental, o que promete, na seqüência, um novo ciclo de aridificação com enxurradas violentas. $\mathrm{O}$ desmatamento da Amazônia, por exemplo, vai intensificar em muito esses processos.Durante muito tempo, especulava-se sobre a causa do colapso da grande Civilização Maia, da América Central. Esse povo produziu grandes cidades e obras de arte, como as grandes civilizações do Velho Mundo o fizeram. Seus matemáticos e astrônomos não tinham igual até recentemente. O que aconteceu com essa Civilização?

A região habitada pelos Maias é rica em calcário e essa pedra foi usada não só como pedra bruta mas também para estuque e para cimento (sim, cimento!), indispensável na realização se obras em concreto. Só que, para reduzir o calcário a cimento, era 
necessário muito calor numa estufa, e o combustível óbvio para isto era a lenha. Esta vinha das muitas árvores da floresta tropical.

As cidades foram ficarndo maiores e as florestas escassas, até o ponto de o solo, sem proteção, ser lixiviado e levado pelas enxurradas, não podendo mais sustentar a grande densidade demográfica dessa civilização urbana. O resultado foi semelhante ao que já notamos na Mesopotâmia. Aliás, a história do Grande Tenochtitlán, das terras altas do México Central, também não foi diferente.

\section{B - Arqueologia na Sala de Aula}

A Arqueologia é uma ciência social que usa métodos e técnicas semelhantes às de outras ciências e um raciocínio metodológico semelhante ao das ciências forenses ou ao da criminalística. Sendo assim, a sua contribuição na sala de aula pode - e deve - ser maior de que uma fonte de informações suplementares para a história.

Arqueólogos nos Estados Unidos incluem no currículo matérias tais como a Arqueologia Urbana. Só que, em vez de cavar buracos, ficam observando, medindo, registrando e analisando relações espaciais entre atividades humanas e a disposição final dos objetos utilizados numa atividade, visando a algum objetivo. Em Massachusetts, alunos foram aos cemitérios para fotografar, medir e analisar estilisticamente as lápides, usando a data do enterro como controle. Conseguiram elaborar sequiências de evolução da idéia de uma lápide adequada. Em Nova York, alunos mediram em centímetros o espaço nas prateleiras dos supermercados para certos produtos, tais como whisky ou manteiga, anotando tanto as marcas, com a sua "carga" de prestígio, quanto a natureza social do bairro onde o supermercado se localizava. Uma comparação foi feita entre medidas em bairros populares, bairros de classes privilegiadas, e ainda com controles, tais como a inspeção do conteúdo das latas de lixo no mesmo bairro e a procura e quantificação das mesmas marcas.

Na década de 1980, usamos uma técnica semelhante, na disciplina de Arqueologia na UFRN, ao enviar os nossos alunos para anotar as marcas e anos dos carros nos estacionamentos perto de comércios ou agremiações (igrejas, country clube, grêmios esportivos, supermercados, etc.) à procura de um índice de co-variação. Também os alunos usaram, experimentalmente, diversas tecnologias de produção de instrumentos de pedra lascada com desenhos e observações analíticas codificadas, em fichas, para aplicar testes estatísticos de níveis de significado de co-variações, como método de ensino da metodologia científica.

Em Portugal, certos professores também estão utilizando a produção e o uso de objetos de pedra e de cerâmica num ambiente apropriado, para ensinar de modo gráfico o estilo de vida dos nossos antepassados e a forma como faziam uso da tecnologia e do meioambiente. Recomendamos ao leitor a consulta do blog do grupo em questão ${ }^{5}$.

\section{C - Questões “quentes” no Contexto Arqueológico}

Ainda há uma classe de fenômenos dos quais a Arqueologia apresenta evidências ou, ao menos, coisas sobre o que se pensar. São as "questões quentes" filosóficas.

Primeiro, o Tempo. A Arqueologia lida com este, e isto que fica manifesto na sequiência de camadas ou na seriação de conjuntos quantificados de artefatos. Mas, o que é o Tempo?

Quando se fala em tempo, pensamos imediatamente em relógios ou em cronologias. A Arqueologia lida com cronologias absolutas (calendário) e relativas ("Antes da 
República, mas depois da Colônia"). Não deve haver qualquer dúvida sobre o que seria isto. Também lidamos com o tempo "objetivo" (relógio, movimentos de corpos celestes) e o tempo "subjetivo" ("Esperei uma eternidade antes de ser atendido" ou "O dia passou num instante"). Também não deve haver nenhum senão aqui.

No entanto, nenhuma dessas idéias sobre o tempo entra na questão essencial: qual é a natureza do tempo?

A gramática das línguas indo-européias divide as ações ou os processos em passado, presente e futuro. Isto nos dá uma imagem do tempo como uma linha, começando num passado desconhecido através do presente até um futuro também desconhecido. Assim, as nossas vidas são uma viagem, como um trem que vai de Curitiba ao Rio de Janeiro, passando por São Paulo.

Mas, outras línguas têm outras estruturas e, portanto, outras visões do tempo. Algumas línguas indígenas classificam os eventos em termos de processos inacabados e processos acabados. Ao se traduzir para uma língua do grupo europeu, o segundo tipo de processo é traduzido como tempo passado, enquanto o primeiro como presente ou, raramente, futuro. Alguns povos pensam que as coisas sempre estiveram como agora; outros, por sua vez, pensam em ciclos, como os astecas, que acreditavam que ocorrera uma sucessão de mundos criados e destruídos e que estávamos num desses ciclos.

A idéia da ciclicidade é tão fundamental quanto à de linearidade e, potencialmente, tem o mesmo valor. Certamente, a ciclicidade está mais de acordo como o que sabemos sobre mudanças climáticas, ascensão e queda de civilizações e assim por diante. Outros aspectos do tempo-espaço estão embutidos nas línguas, como o hopi que diz "Ontem à noite eu estive com a roseira da minha mãe" em vez de como nós, "Ontem à noite eu sonhei com a roseira da minha mãe". Quem tem razão? O que a ciência moderna nos diz sobre o tempo?

A Ciência diz que o Universo consiste se energia, sendo uma das formas desta a matéria. Outros acrescentam outra coisa a esse quadro, a qual, ao contrário da matéria e da energia, não pode ser vista diretamente: trata-se da organização ou informação. Como diz o antropólogo Radcliffe-Brown, dizer que uma cultura podia se alastrar através de um continente é como dizer que uma equação quadrática pode cometer um assassinato. Não se pode ver um clã, mas ninguém que estude um povo que o tem pode duvidar que lá esteja mesmo invisível. É que a informação não tem existência física, não estando, portanto, sujeita às leis da Termodinâmica.

Físicos, tais como Heisenberg, dizem que a passagem do tempo é, no mínimo, um efeito colateral da entropia ${ }^{6}$ ou, no máximo, uma ilusão provocada por esta. Isto significa que, para voltar no tempo, você tem que repor, no lugar certo, todas as energias entrópicas gastas por um processo qualquer. Vamos considerar, por exemplo, queimar lenha. Como fazer a energia dissipada, como o calor, voltar à lareira e se reconstituir como lenha? A quantidade de energia envolvida é simplesmente impensável. É por isso que os processos entrópicos complexos são irreversivos. Isto inclui o tempo. Evidentemente, é impossível juntar energia do Universo o suficiente para se voltar no tempo, a não ser que se passe por um universo paralelo.

Em outras palavras, a resposta à pergunta, "O que é o Tempo?" só pode ser: "Não sei, nem sei se existe."

Outra questão "quente" ligada à do Tempo, é a da sobrevivência. Entendemos a sobrevivência como sendo a permanência do indivíduo ou da espécie, mas isto tem que ser qualificado em termos de tempo, pois envolve adaptabilidade e adaptação às circunstâncias ambientais. Mas, se representarmos isto num circuito, descobriremos que "maximizar a adaptação" significa "maximizar as atividades de procura", o que é um circuito de 
ampliação (ver MILLER, 2009a). Essa ampliação conduz à exauração das fontes de energias/matérias procuradas, o que conduz à decadência do sistema. Adaptação, no sentido de maximização, portanto, não conduz à sobrevivência, como vimos nos casos da Mesopotâmia e da América Central. Adaptabilidade significa a capacidade de amortecer as atividades de procura para dentro da capacidade do ambiente as sustentar, em vez de ampliá-las. Na Amazônia, os índios são quase os únicos que entendem isto em nível da prática. Não entender isto é trazer mudanças climáticas, pragas, fome e conflitos.

Finalmente, queremos examinar outra "questão quente", a saber: "O que é o Progresso?"

Presume-se que o progresso seja um concomitante da evolução e signifique ir ("Progredir") para uma coisa melhor do que a anterior. Progresso representa mais, maior, melhor, etc. No Paleolítico, o homem teve que dar duro para buscar e caçar alimentos. No Neolítico, as coisas melhoraram porque a domesticação de plantas e animais conduziu a uma produção maior, o que significou fartura e tempo de lazer. Melhor ainda foi com a civilização, com a especialização de funções sob uma coordenação, o que resulto em mais produtos e mais conforto para todos. Todo mundo sabe disso, não sabe?

Vamos começar com a jornada do trabalho. De acordo com antropólogos que trabalhavam em lugares como o Deserto do Kalaari, onde a produção natural de elementos é baixa, existe um povo (os san) que lá vive desde tempos imemoriais, e os seus restos arqueológicos se encontram por toda parte da África. Como no caso de todos os Bandos Patrilocais, o modo de vida mais bem-sucedida da história do homem (mais de cem mil anos), as mulheres coletam e processam produtos vegetais e os homens caçam as proteínas na forma de animais. Em quatro a seis horas, um homem pode apanhar comida suficiente para a sua família para três, quatro ou mais dias. No resto do tempo, ele fabrica e conserta os seus instrumentos de trabalho, conversa com a família ou com os vizinhos, troca histórias de eventos e atividades para educar os seus filhos e tira sonecas. Imaginemos como seria esse modo de produção num ambiente que não seja pobre como o Deserto do Kalaari!

No entanto, o caçador-coletor tem que mudar freqüentemente o seu acampamento, pois os recursos locais se esgotam. Isto significa que não pode acumular propriedades - ele é pobre, portanto ninguém vai atacá-lo para roubar riquezas que ele não tem. Ao mesmo tempo, não poder levar peso significa não poder ter muitas crianças para levar de um local para outro. Além do mais, mais bocas para alimentar significa ter que mudar o acampamento com maior frequiência.

O agricultor, ao contrário, tem a sua produção perto da mão, não tendo que correr atrás. Fora os curtos períodos de semear e coletar, ele trabalha uma média de três ou quatro horas também, mas aqui é todo dia. Trabalho pesado é o de brocar a mata para fazer roça. Depois da colheita, ele tem os seus alimentos estocados para passar a entressafra e pode acumular riquezas e filhos. Acumular filhos significa ter que aumentar a roça e, portanto, o trabalho. Aumentar riquezas e alimento estocado atrai saqueadores.

O agricultor não ganha tempo de ócio pela sua nova atividade econômico; ganha a possibilidade de ter mais filhos porque não tem que constantemente mudar $o$ acampamento.

E, nos tempos modernos? A jornada de trabalho é de 8 horas por dia, de 40 a 48 horas semanais, o ano todo - fora as férias. Isto porque movimentos trabalhistas acabaram com a jornada de 10 a 12 horas sem período de férias, o que era normal para as civilizações. O civilizado trabalha mais, não menos, de que o agricultor do Neolítico.

Para viver numa comunidade com especializações de profissões, inclusive para protegê-lo de assaltantes, o civilizado tem que sustentar, além dos especialistas, uma 
administração, que logo se torna uma classe dirigente, e pagar impostos. Para isto, ele tem que trabalhar mais (se for independente) ou pegar um segundo emprego, a sua esposa tem que pegar um emprego além de continuar a gerenciar o lar - o civilizado trabalha mais ainda de que o homem do Neolítico.

Um índio brasileiro que tinha morado no Rio de Janeiro foi entrevistado na tribo e lhe perguntaram se ele tinha gostado da cidade. Disse que sim. Então perguntaram porque voltara para a tribo. "Porque aqui não tem que pagar o aluguel, não tem que pagar a conta do telefone, não tem que pagar a conta da água, da luz, não tem que pagar impostos, não tem lojas cheias de coisas para comprar - aqui na tribo tudo é mais fácil."

O que é que o civilizado ganha? Mais tempo de lazer não. Ganha uma maior escolha de objetos de consumo sem ter de os fazer a mão, mas para pagar para tanto tem que trabalhar mais ou comer menos. Ele pode até sonhar em um dos seus filhos chegar a trabalhar para a classe dirigente e ter uma vida de maior conforto ou luxo.

A esse ponto, devemos nos perguntar: o que é que queremos da vida? Mais tempo, dinheiro, comida, conforto, felicidade, mais filhos vivos? Menos trabalho, angústia, preocupação? O que é que nos proporciona as coisas que queremos? É a domesticação de plantas, a civilização, as contas bancárias, os bens de posse?

Com isto não estamos propondo uma volta da humanidade ao Paleolítico: isto é impossível. Mesmo se tentasse fazer isto algum salteador com mais organização e equipamento bélico nos levaria de volta ou nos destruiria. As mudanças entrópicas, inclusive o tempo, são unidirecionais. Mas se podemos instituir uma jornada de 8 horas e férias, pela lei, podemos fazer outros melhoramentos também, só que teremos que reduzir a densidade demográfica que pressiona a capacidade limitada da terra de nos sustentar. Temos que aprender a fazer o que fizeram no Paleolítico: controlar o número de nascimentos.

Ainda, devemos colocar tudo isto em termos de todos, pois tem-se que lembrar que a liberdade de um há de terminar onde começa a do outro. O filósofo iluminista Thomas HOBBES (1979) diz que somente uma pessoa no mundo (civilizado) pode ser livre: o soberano.

Quais são as coisas permanentes, portanto confiáveis na vida? A resposta do antropólogo Melville HERSKOVITS (1963) é “A mudança”. Um ditame popular diz que são duas: a morte e os impostos.

Escrevemos e lemos a nossa História do nosso ponto de vista, ainda como sobreviventes. Esquecemo-nos de que a paisagem paleontológica e arqueológica está entulhada de restos de espécies e civilizações elegantes, porém, extintas. Estamos olhando do ponto errado do telescópio. A Arqueologia pode nos ajudar a pensar um pouco sobre quais são as nossas perspectivas.

\section{BIBLIOGRAFIA}

BINFORD, Lewis --- "Archaeology as Anthropology." American Antiquity, vol. 28: 217-25, 1962.

--- "A consideration of archaeological research design." American Antiquity, vol. 29: 425-41, 1964.

BEZERRA DE MENEZES, Ulpiano Toledo - "A Cultura Material no Estudo das Sociedades Antigas". Trabalho apresentado ao $1^{\circ}$ Simpósio Nacional de História Antiga, João Pessoa, PB., 1983. 
GAMBINI, Roberto - artigo sobre as nossas origens publicado em "Os Caminhos da Terra" na sua edição de junho de 1998.

HOBBES, Thomas --- Leviatã. 2a ed. São Paulo: Abril Cultural, 1979. Orig. 1651.

HERSKOVITS, Melville --- Man and his Works: Antropologia Cultural. São Paulo: Mestre Jou, 1963.

MALINOWSKI, Bronislaw --- Uma Teoria Científica da Cultura. Rio de Janeiro: Zahar, 1970.

MILLER, T. O. --- A Segunda Revolução Científica: Como o pensamento sobre o Universo chegou a se transfigurar nos últimos anos, na visão de um AntropólogoArqueólogo Transdisciplinar. Natal: Editora Universitária. 2009a. No prelo.

--- "O Papel da Arqueologia na Educação Patrimonial" In, SARTI, Antonio Carlos; MUNDET, Lluís (orgs).Turismo e Arqueologia: múltiplos olhares. Piracicaba: PrintFit, 2009b. No prelo.

PARREIRAS HORTA, Maria de Lourdes -- "Educação Patrimonial.” Apostila. s.d.

RADCLIFFE-BROWN, A. R. --- Estrutura e Função na Sociedade Primitiva. Petrópolis: Vozes, 1973. Orig. 1952

RIBEIRO, Darcy --- O povo brasileiro. São Paulo: Círculo do Livro, 1995 


\section{Notas}

1. Professor aposentado do Departamento de Antropologia e do Museu "Câmara Cascudo" da Universidade Federal do Rio Grande do Norte.

2. A Historicidade se refere à concatenação única de experiências que impingem e, portanto, afetam a cada indivíduo - seja pessoa, folha, passarinho, célula, montanha ou qualquer coisa. Assim, cada indivíduo é único, pois não há duas histórias individuais idênticas. No nosso pensamento cognitivo, juntamos fenômenos em classes rotuladas, como estas que acabamos de citar, e daí tratamos a classe como se fosse um fenômeno discreto por si só.

3. O Antropólogo A.R. RADCLIFFE-BROWN define a Função como sendo a "contribuição parcial que uma determinada prática faz para a manutenção" ou prolongamento da vida do sistema do qual faz parte. Isto é diferente do Significado, o que é alguém ou uma sociedade entende ser um fenômeno, independentemente de se realmente for ou não a mesma coisa. $\mathrm{Na}$ lingüística, é o valor convencionado a um símbolo.

4. As Normas são regras de procedimento prescritas por um sistema e, aplicadas pela filtragem de inputs e outputs. No caso de sistemas socioculturais, as normas são coisas de valores, bons modos e etiqueta.

5. Recomendo ao leitor a consulta do blog do grupo português em questão, é http://www.arqueologiaexperimental.blogspot.com/

6. Entropia: o constante de desperdício de energia perdida em todas as transformações energéticas do Universo. Pela entropia, o ponto final do Universo seria, eventualmente, uma distribuição aleatória e homogênea (desorganizada) de energia.

Artigo recebido em: 27/05/09

Aprovado para publicação em: 31/07/09 